\title{
Derivation Method for Determining Sorbitol in Fruit Trees
}

\author{
Regina Célia Faria Simão Canesin*, William Deodato Isique, Salatiér Buzetti, \\ Juliana Aparecida de Souza \\ University of São Paulo State (UNESP), Ilha Solteira Campus, Ilha Solteira, Brazil \\ Email: ${ }^{*}$ reginacanesin@agr.feis.unesp.br
}

Received 10 September 2014; revised 9 October 2014; accepted 5 November 2014

Copyright @ 2014 by authors and Scientific Research Publishing Inc.

This work is licensed under the Creative Commons Attribution International License (CC BY). http://creativecommons.org/licenses/by/4.0/

c) (i) Open Access

\begin{abstract}
The goal of this study is to describe a methodology for the analysis of D-sorbitol using benzyl alcohol as derivatizing agent and liquid chromatography equipped with a diode-array detector (HPLC-DAD). The study was performed at the University of São Paulo State (UNESP), Ilha Solteira Campus, Brazil. The axillary buds of fruit trees were collected from the UNESP Teaching and Research Farm. Benzyl alcohol was used as derivatizing agent to extract D-sorbitol from the buds. Next, the D-sorbitol underwent solid phase extraction (SPE) using $\mathrm{C}_{18}$ cartridges and was then analyzed by liquid chromatography (HPLC-DAD). The HPLC-DAD derivatization method proposed showed excellent chromatography resolution and high accuracy in the separation of D-sorbitol (derivatized) for the axillary buds of avocado, black mulberry, Japanese pear and peach and also enabled eliminating the use of hazardous derivatizing agents.
\end{abstract}

\section{Keywords}

Benzyl Alcohol, Polyols, HPLC-DAD

\section{Introduction}

The so-called polyols or polyhydroxy alcohols are reduced forms of sugars which are probably ubiquitous in all plant species [1]. The most common polyols are derived from hexose sugars through the reduction of aldose or ketose, which are reduced to a hydroxyl group by aldose reductase (alditol/NADP ${ }^{+}$oxidoreductase, E.C.1.1.1.21, ALR2), considering it the first enzyme in the polyol pathway which reduces D-glucose to D-sorbitol, and with the concomitant conversion of NADPH to NADP [2]. Therefore, mannitol, sorbitol (or glucitol) and dulcitol (or galactitol) are the equivalent polyols of hexose glucose, fructose and galactose, respectively, and are hexitols

${ }^{*}$ Corresponding author.

How to cite this paper: Canesin, R.C.F.S., Isique, W.D., Buzetti, S. and de Souza, J.A. (2014) Derivation Method for Determining Sorbitol in Fruit Trees. American Journal of Plant Sciences, 5, 3457-3463.

http://dx.doi.org/10.4236/ajps.2014.523361 
frequently found in angiosperms [3].

As mannitol is the most abundant polyol in nature, it participates in the translocation and storage of metabolites, in addition to providing resistance to salinity and osmotic stress in plants [3], and it can also act as protection against invading pathogens [1]. D-sorbitol is a primary product of photosynthesis and studies have shown that it is very common, especially in fruit [1]. It is very abundant in some species, such as in apple and also in mulberry. D-sorbitol has approximately the same levels as sucrose [4].

Despite the importance, occurrence, metabolism and physiology of polyols in plants, studies are needed for this type of compound as its function in plants is not completely known. The absence of a chromophore cluster (benzene ring) in the molecule of D-sorbitol results in the disadvantage of high performance liquid chromatography analysis (HPLC), as it precludes its detection by the absorbance of non-derivatized sugar at wavelengths above $200 \mathrm{~nm}$.

The non-derivatized sugars can usually be analyzed and quantified using a variety of chromatographic methods in conjunction with different types of detectors such as: refraction rate, electrochemical detection and currently by evaporative light scattering detection. Absorbance and fluorescence detection has advantages such as: low cost, derivatization feasibility in pre and post-column stages of carbohydrates, increased sensitivity and selectivity detection [5].

The pre-column derivatization of sugars using compounds that have strong UV-adsorbent chromophore facilitates monitoring absorbance at the 230 to $280 \mathrm{~nm}$ region. The benzylation process covers a large class of substances containing hydroxyl, amino groups and other compounds, which in the presence of water results in UV-active derivatives that are suitable for extraction in organic solvents [2]. The benzene radical easily connects to hydroxyl groups of several molecules, also including the sugars and polyhydroxy alcohols. Since these groups develop double bonds, the derivatives containing the benzene radical absorb in the UV-visible molecules of any source. Thus they can be detected by a UV type detector [6].

Considering the difficulties in the microanalysis method (detection and quantification) of sugars and polyalcohols (mannitol and sorbitol), as well as the costly liquid-liquid extraction technique used in gas chromatography (GC), this study describes a methodology for the analysis of D-sorbitol using benzyl alcohol as derivatizing agent and liquid chromatography equipped with a diode array detector (HPLC-DAD).

\section{Materials and Methods}

The study was carried out at the Sanitation Laboratory of the University of São Paulo State (UNESP), Ilha Solteira Campus, Brazil. Axillary buds from shoots were collected at UNESP Teaching and Research Farm, the fruit trees were: avocado (Persea americana Mill); black mulberry (Rubus brasiliensis); Japanese pear (Pyrus pyrifolia var culta) and peach (Prunus persica), guava (Psidium guajava L.) and mango (Mangifera indica L.).

\subsection{Sample Preparation}

The axillary buds of fully developed leaves located in the branches, in that period of growth, were collected in 10/09/2009. The shoots were kept separate in methanol (MeOH 80\%) and under refrigeration prior to the benzylation steps and solid phase extraction of sorbitol.

The bud samples were dried in an oven at $65^{\circ} \mathrm{C}$ for 24 hours, to later determine the mass of each sample using a 5 digit analytical balance. These samples were then macerated in a $10.0 \mathrm{~mL}$ Hach tube using a polyethylene stick. $2.0 \mathrm{~mL}$ of $\mathrm{MeOH}(100 \%)$ were used for the liquid phase extraction of sorbitol. The samples were then homogenized for 15 min using a vortex (BiomiXer). The macerated sediment was filtered using a qualitative filter paper and then underwent the derivatization step.

\subsection{Derivatization}

The methods proposed in [7] and [6] were used in the benzylation step (pre-column derivatization). The benzylation was performed with $50.0 \mu \mathrm{L}$ of benzyl alcohol concentrated in the fruit tree bud samples, and homogenization was performed by vigorous shaking in the vortex for $1.0 \mathrm{~min} ; 50.0 \mu \mathrm{L}$ of benzyl alcohol concentrate was again used to facilitate the benzylation reaction of the other compounds that could be present in all samples; a new homogenization was carried out for 1.0 to $2.0 \mathrm{~min}$ and then $100.0 \mu \mathrm{L}$ of sodium hydroxide (8 M) was added and all samples were homogenized for $5.0 \mathrm{~min}$. Using a digester (Hach-DRB 200), the samples were left to 
rest for $20 \mathrm{~min}$ at $30^{\circ} \mathrm{C}$, then neutralization (basifying) of the samples was performed with $100.0 \mu \mathrm{L}$ of phosphoric acid (1.4 M) and then homogenization was carried out for $1.0 \mathrm{~min}$.

The benzylated sorbitol in the fruit tree bud samples was subjected to solid phase extraction $\left(\mathrm{C}_{18}\right.$ cartridges $)$ [6]. The $\mathrm{C}_{18}$ cartridges were initially pre-activated with $10.0 \mathrm{ml}$ of $\mathrm{MeOH}(100 \%)$ and $10.0 \mathrm{~mL}$ of Milli-Q water at a flow rate of $3.0 \mathrm{~mL} \cdot \mathrm{min}^{-1}$; the derivatized samples were then eluted at a speed of $3.0 \mathrm{~mL} \cdot \mathrm{min}^{-1}$; next, 2.0 $\mathrm{mL}$ of Milli-Q water was added and the eluate was collected by the addition of $500 \mu \mathrm{L}$ of acetonitrile $(60 \%)$ and then again the addition of $500 \mu \mathrm{L}$ of acetonitrile (100\%).

\subsection{Validation of the Method}

For the method validation a spread sheet proposed in [8] was used to analyze the following parameters: selectivity, adjustment of the analytic curve and determination of its linearity range, sensitivity of the method, represented by the limits of detection (LD) and quantification (LQ), precision, accuracy and robustness. The recovery (which evaluates the efficiency of the method) of sorbitol was carried out through three aliquots $(0.04 ; 0.070$ and $0.1 \mu \mathrm{g} \cdot \mathrm{mL}^{-1}$ ) resulting from the analytical curve of the D-sorbitol samples (HPLC grade) and benzyl alcohol/ $\mathrm{NaOH}$ (basification), whose samples were subjected to solid phase extraction using $\mathrm{C}_{18}$ cartridges as described earlier. The samples were injected into the HPLC five times [9].

A way to ensure the applicability and scope of a method for the routine operations of a laboratory is establishing the limits of parameters from the estimation of figures of merit, known as a validation step [8].

Quantitative indicators of the scope and the good performance of the techniques, and are described in the literature as: selectivity, adjust the calibration curve and determination of its linearity range, sensitivity of the method represented by the limits of detection (LD) and quantification (LQ), precision, accuracy and robustness [10]-[12].

Selectivity is the ability to assess unequivocally the substances under examination in the presence of components that may interfere with their determination in a complex sample [9]. This ensures that the signal is not affected by interfering substances.

Linearity expresses the range in which the analytical signal, called the dependent variable $y_{i}$ is linearly proportional to its concentration, called the independent variable $x_{i}$, and the mathematical equation that describes this dependence is known as calibration curve or calibration curve [8].

Adjusting any mathematical equation is done by the least squares method, in which the best curve will be one that will provide the lowest value for the sum of the quadratic residues $(Q)$ obtained between the measured analytical signal $\left(y_{i}\right)$ and the predicted analytical signal $\left(\hat{y}_{i}\right)$ for a set $N$ data points. The curve fit using the method of least squares regression coefficients provide, in the case of a linear fit $\left(y_{i}=a_{0}+a_{1} x_{i}\right)$ is linear $\left(y_{i}=a_{0}+a_{1} x_{i}\right)$ and angular coefficients $\left(a_{1}=\sum\left[\left(x_{i}-\dot{X}\right) \cdot\left(y_{i}-\bar{Y}\right)\right] / \sum\left(x_{i}-\dot{X}\right)^{2}\right)$, where $x$ is the mean value of the concentration $\left(x_{i}\right)$ to the total number of samples $(N)$ used as calibration standards.

The sensitivity of a method is defined by the limits of detection (LD) and quantification (LQ). The LD is the lowest concentration of the species of interest that can be detected by instrumental technique, while the LQ is the lowest concentration that can be quantified within the limits of precision and accuracy of the method during routine operation of the laboratory, under usual conditions [8].

The LD and LQ can be estimated based on the parameters of the analytical curve method [8]. The method of estimation of LD based on parameters of the analytical curve shows greater statistical reliability because it takes into account the confidence interval of the regression [8]. LQ can be determined by analysis of samples with known concentrations of the species of interest and corresponds to the lowest concentration that can be quantitated within the limits of accuracy and precision of the method [9]. The LQ is calculated from the confidence interval of the analytical curve.

The term provides precisely the dispersion of the measured values around a mean value, and its numerical value is estimated by the relative standard deviation, RSD or ("relative standard deviation") for analysis of samples containing the same amount of the species of interest [8].

The accuracy can be estimated at three levels: repeatability, intermediate precision and reproducibility [8]. The term repeatability, accuracy or within-run precision, defines the accuracy of the results obtained within the laboratory itself, by the same analyst with the same instrumentation. The intermediate precision, accuracy or iter-run defines the precision within a laboratory for measurements obtained by different analysts, or on different days or for different equipment. The term reproducibility defines the accuracy of the results obtained for a given 
analysis performed by different laboratories, but following the same methodology. The precision reflects the closeness of the measured value $\left(x_{i}\right)$ and a reference value considered true $\left(x_{v}\right)$ and is correlated with the absolute error of a measured [8].

The robustness of a method is its ability to withstand small variations of the analytical parameters without significantly altering its accuracy and precision, thus is a measure of the amount of variability that the method can support without losing reliability, and its estimate depends on the type of analytical methodology. The robustness of a method may be estimated by varying the analytical parameters and comparing the precision obtained in each determination [8].

\subsection{Chromatographic Conditions}

The chromatographic analysis was performed in two phases, the first step was qualitative and the second quantitative. In the first stage the objective was to detect sorbitol in the bud and in the second step the quantification of sorbitol in the species in which its presence was detected.

Chromatography was performed using a Shimadzu HPLC system equipped with an LC column chromatography Column Shim-pack $\mathrm{C}_{18}\left(250 \mathrm{~mm} \times 4.6 \mathrm{~mm}\right.$ ID, $5.0 \mu \mathrm{m}$ particles) with a guard Column Shim-pack $\mathrm{C}_{18}$ (50 $\mathrm{mm} \times 4.6 \mathrm{~mm}$ ID, $5.0 \mu \mathrm{m}$ particles). Elution was carried out using acetonitrile-water (gradient of $20 \%$ to $80 \%$ of acetonitrile for $30 \mathrm{~min}$ ). The detection of the chromatographic peaks was performed by a SPD-M20A detector (prominence Diode Array detector) using wavelengths at $228 \mathrm{~nm}$ and $248 \mathrm{~nm}$. The chromatograms were integrated using the LC solution software.

\section{Results and Discussion}

The $\mathrm{C}_{18}$ LC Column Shim-pack column showed excellent chromatographic resolution and a clear separation of D-sorbitol (derivatized) with different degrees of purity (Figure 1(a)) and the axillary buds of fruit trees such as: avocado, black mulberry, Japanese pear and peach (Figure 1(b)) respectively.

Table 1 shows the parameters values of: sensitivity (LD and LQ), precision and accuracy performed by the analytical curve of the derivatized D-sorbitol and recovery (SPE). According to the Student's T test ( $t_{\text {calculated }}$, there are no significant differences between the recoveries and the expected value (100\%), since all the absolute values of $t_{\text {calculated }}$ are smaller than the value tabulated for $t$, therefore it was found that the method used for the microanalysis of derivatized D-sorbitol can be considered precise and accurate.

The intervals for the coefficients of variation (1.4 to 8.6) resulting from the recovery of D-sorbitol proved to be suitable, since they do not exceed the limits (20\%) [8].

Thus, the results in Table 1 regarding the accuracy and precision requirements for the fortifications levels studied on the same day, with the same analyst for the method used; with the same instrument and at the same location, with repetitions at short time intervals, verifies the efficiency for the method used to quantify the derivatized D-sorbitol.

Table 1. Parameter values of: limits of detection (LD) and quantitation (LQ), precision and accuracy for the derivatization method of D-sorbitol conducted by a validation spreadsheet proposed in [8].

\begin{tabular}{|c|c|c|c|c|}
\hline \multicolumn{5}{|c|}{$\begin{array}{l}\text { Analytical curve of D-sorbitol } \\
\left.\text { 0.020;0.048; } 0.075 \text { and } 0.10 \mu \mathrm{g} \cdot \mathrm{mL}^{-1}\right]\end{array}$} \\
\hline \multicolumn{5}{|c|}{ Sensitivity } \\
\hline LD (linearity at 95\%) & LQ (linearity at 95\%) & $R^{2}$ & & $Y=8650794.73 x$ \\
\hline $0.03 \mu \mathrm{g} \cdot \mathrm{mL}^{-1}$ & $0.14 \mu \mathrm{g} \cdot \mathrm{mL}^{-1}$ & 0.99 & & - \\
\hline \multicolumn{5}{|c|}{ Recovery (solid phase extraction) } \\
\hline $\begin{array}{l}\text { Fortification level estimated } \\
\qquad\left(\mu \mathrm{g} \cdot \mathrm{mL}^{-1}\right)\end{array}$ & $\begin{array}{l}\text { Fortification level determined } \\
\qquad\left(\mu \mathrm{g} \cdot \mathrm{mL}^{-1}\right) X \pm \sigma\end{array}$ & $\%$ of recovery & C.V. (\%) & $\begin{array}{l}\text { Student } \\
t_{\text {calculated }}\end{array}$ \\
\hline 0.040 & $0.039 \pm 0.0030$ & $98.0(96-99)$ & 7.9 & 0.103 \\
\hline 0.070 & $0.077 \pm 0.0011$ & $110.0(95-100)$ & 1.4 & 0.002 \\
\hline 0.100 & $0.096 \pm 0.0080$ & $96.0(101-103)$ & 8.6 & 0.016 \\
\hline
\end{tabular}

$R^{2}$ : correlation coefficient; $X$ : average of quintuplicates; $\sigma$ : standard deviation; C.V.: coefficient of variation. 


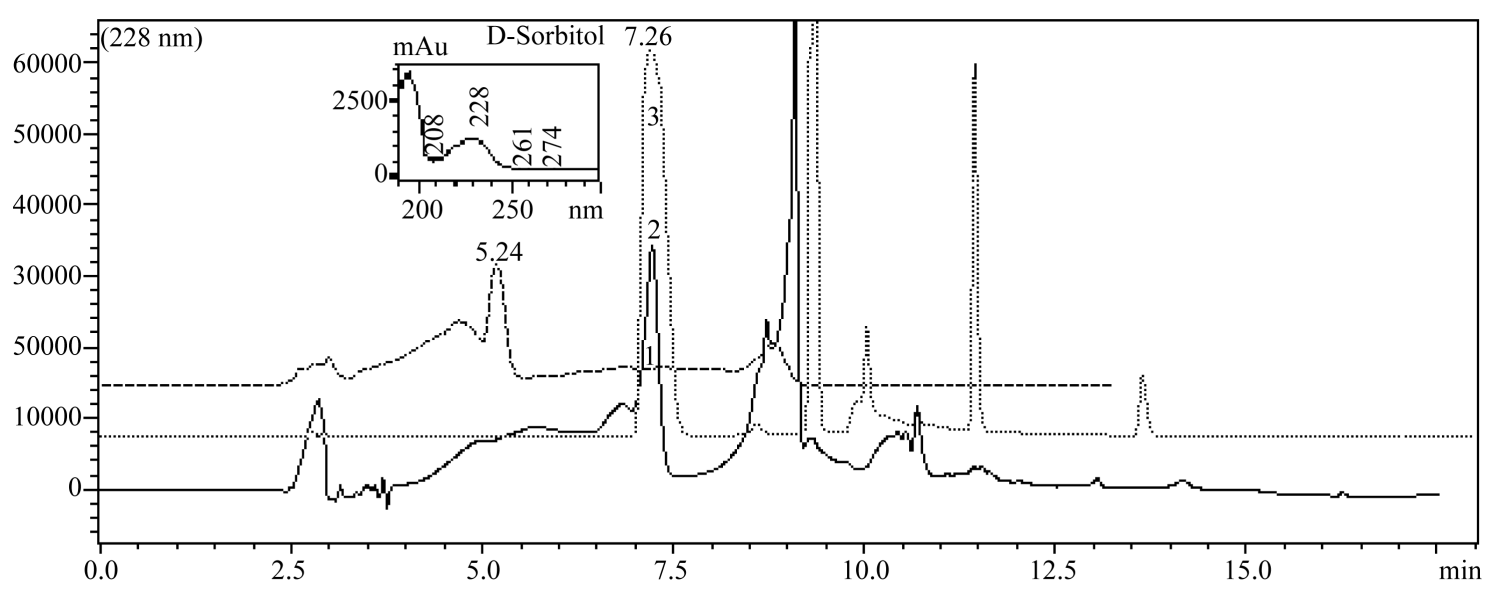

(a)

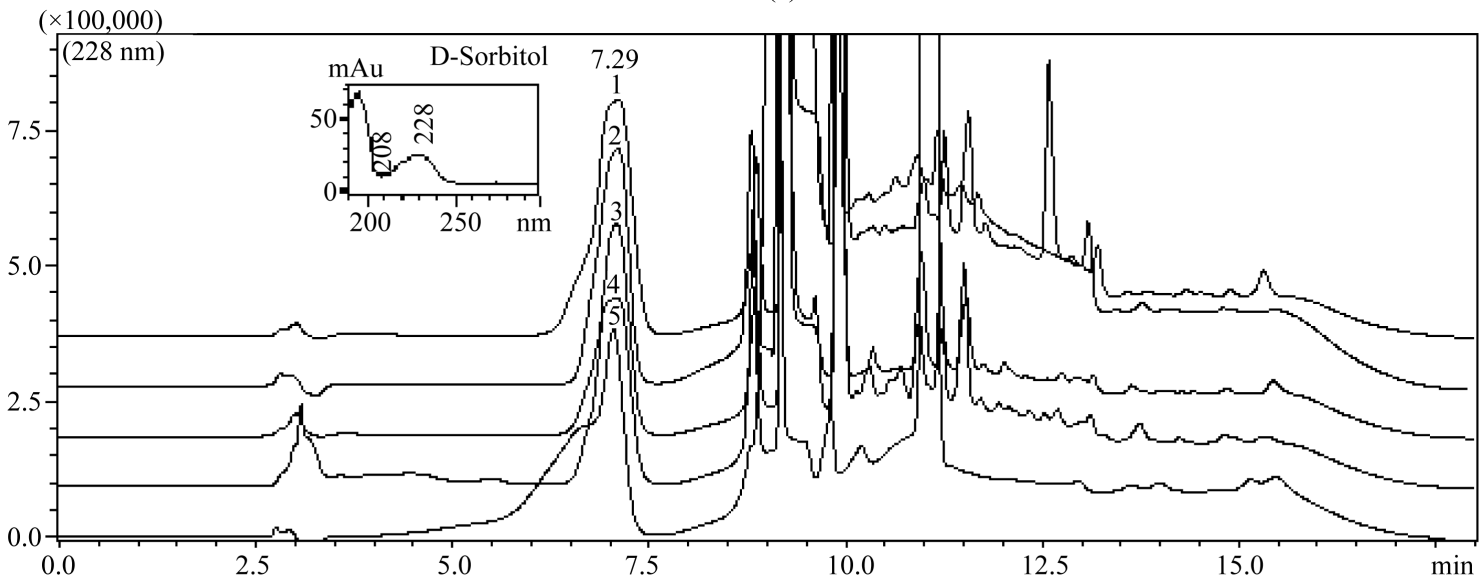

(b)

Figure 1. (a) Spectrophotometric and chromatographic profiles of derivatized D-sorbitol. (1) Benzyl alcohol (T.r. 5.24); (2) derivatized D-sorbitol HPLC grade (T.r. 7.27) and (3) commercial use derivatized D-sorbitol (T.r. 7.27). LC column shim-pack $\mathrm{C}_{18}(250 \mathrm{~mm} \times 4.6 \mathrm{~mm}$ ID, $5.0 \mu \mathrm{m}$ particles), detection at $228 \mathrm{~nm}$; (b) Chromatographic profiles of derivatized D-sorbitol found in the buds of different fruit species. (1) Avocado, (2) black mulberry, (3) Japanese pear, (4) peach, (5) derivatized D-sorbitol (5.0 $\mu \mathrm{m}$ particles). LC column shim-pack $\mathrm{C}_{18}(250 \mathrm{~mm} \times 4.6 \mathrm{~mm}$ ID, $5.0 \mu \mathrm{m}$ particles), detection at $228 \mathrm{~nm}$.

The derivatives of D-sorbitol-benzyl absorbing ultraviolet light resulting from the reaction between the Dsorbitol (HPLC grade) and benzyl alcohol/NaOH (basification) and also the macerated axillary buds of fruit trees showed stability for several hours ( 24 to 48 hours), allowing them to be detected and quantified by HPLC. In the present study the use of benzyl alcohol as reagent of benzylation for the microanalysis of polyols (sorbitol) are also in agreement with [7] and [13] with respect to the stabilization time of the derivatization reaction. These authors also observed a reduced stabilization time in the reaction of benzoyl chloride with D-sorbitol in sugar, polyols and amino acids from human biological fluid samples.

Table 2 shows the levels of D-sorbitol (benzylated) of interest in the samples of axillary buds of fruit trees. The fructose, glucose and lactose contents are well known in fruits and vegetables [14], however the levels of sugar polyols (sorbitol and mannitol) are limited to only some literature data.

Studies show that the levels of D-sorbitol may vary between different species or even among the same gender during their maturation stage. Recent studies on different types of fruit have demonstrated a significant difference in the levels of D-sorbitol (grams/100 g of dried fruit) in: blackberry (4.76 g), avocado ( $0.65 \mathrm{~g}$ ), lychee ( $0.53 \mathrm{~g})$, longan $(0.68 \mathrm{~g})$, nectarines $(1.01 \mathrm{~g})$ and depending on the species and type of processing in apples (0.14 to $0.73 \mathrm{~g})$, pear ( 0.90 to $5.99 \mathrm{~g})$ and peach $(0.90$ to $5.99 \mathrm{~g})$ [14].

In this study the levels of D-sorbitol resulting from the averages of three concentrations found in the axillary 
Table 2. Derivatized D-sorbitol levels ( $\mu \mathrm{g} \cdot \mathrm{mg}^{-1}$ dry wt) found in axillary buds of different fruit trees.

\begin{tabular}{|c|c|c|c|}
\hline Fruit tree & Retention time & $\begin{array}{c}\text { D-sorbitol content } \\
\left(\mu \mathrm{g} \cdot \mathrm{mg}^{-1} \text { dry wt) } X \pm \sigma\right.\end{array}$ & C.V. (\%) \\
\hline Avocado (Persea americana Mill) & $7.29(0.06)$ & $0.099 \pm 0.0029$ & 2.10 \\
\hline Black mullberry (Rubus brasiliensis) & $7.29(0.03)$ & $0.042 \pm 0.0025$ & 5.83 \\
\hline Guava (Psidium guajava L.) & n.d. & 0 & 0 \\
\hline Mango (Mangifera indica L.) & n.d. & 0 & 0 \\
\hline Japanese pear (Pyrus pyrifolia var culta) & $7.29(0.51)$ & $0.138 \pm 0.0020$ & 1.41 \\
\hline Peach (Prunus persica) & $7.29(0.08)$ & $0.040 \pm 0.0030$ & 7.41 \\
\hline
\end{tabular}

n.d.: not detected; $X$ : average of triplicates; $\sigma$ : standard deviation; C.V.: coefficient of variation.

buds of fruit trees were limited to the order of $\mu \mathrm{g} \cdot \mathrm{mg}^{-1}$ dry wt (Table 2), obtaining the levels of D-sorbitol in larger axillary buds for Pyrus pyrifolia var culta $\left(0.138 \mu \mathrm{g} \cdot \mathrm{mg}^{-1}\right)$ followed in descending order by Persea americana Mill $\left(0.099 \mu \mathrm{g} \cdot \mathrm{mg}^{-1}\right)$, Rubus brasiliensis $\left(0.042 \mu \mathrm{g} \cdot \mathrm{mg}^{-1}\right)$ and Prunus persica $\left(0.040 \mu \mathrm{g} \cdot \mathrm{mg}^{-1}\right)$. The literature shows that Rubus sp. and Pyrus sp. are the species with the highest levels of D-sorbitol. However, this was not verified for the levels of D-sorbitol in the axillary buds of Rubus brasiliensis (Table 2).

The low activity or the enzyme deficiency of sorbitol dehydrogenase could be a possible explanation for the low D-sorbitol content found in the axillary buds of Rubus brasiliensis and even for Prunus persica [14]. Because it is known that the enzyme NAD-SDH found in fruits (apricot, loquat, apple, peach, pear) and other higher plants (squash, broccoli, fennel, beans, cucumber) [14] is responsible for the oxidation of glucose for sorbitol and fructose [1]. In addition to being considered the key to the metabolic utilization of D-sorbitol, it also plays an important role in carbon supplementation during the development of leaves and fruits [15].

The lack of NAD-SDH or even the lack of activity of this enzyme in many young leaves and also its detection difficulty in mature leaves suggests an interrelationship between the development of the chloroplast, photosynthetic capacity and in turn in the synthesis of D-sorbitol [2]. Studies using experiments with pulse markers $\left({ }^{14} \mathrm{CO}_{2}\right)$ in fully expanded pear leaves demonstrated that D-sorbitol was poorly metabolized and suggested that the regions of meristematic growth activity (such as the axillary buds) were probably using the D-sorbitol, therefore the maturation of plant tissues tend to lose this ability. This report might corroborate the low content of D-sorbitol found in the axillary buds of Rubus braziliensis, which could probably be due to the low activity or even the lack of aldose reduction.

The variation between the D-sorbitol levels can be expected, as previously mentioned, for the different fruit species or even depending on the variations occurring among their own gender, the season, weather, storage time and temperature [16]. Therefore, considering the differences in: maturation, cultivation and geographical location, the results can vary greatly regarding the contents of this polyalcohol [6].

The results demonstrated the occurrence of D-sorbitol in avocado, black mulberry, peach and Japanese pear, which confirms that the polyalcohol is in fact widely dispersed in some fruits, except for: banana, citrus fruits, mango, melon and grapes [4] and [14].

The proposed derivatized D-sorbitol method enabled eliminating the use of the most hazardous derivatizing agents, as well as reducing the running time, when compared to gas chromatography.

\section{Conclusion}

The derivatization method proposed for HPLC-DAD showed excellent chromatography resolution and high accuracy in the separation of D-sorbitol (derivatized) for the axillary buds of avocado, black mulberry, Japanese pear, peach, as well as enabled eliminating the use of more dangerous derivatizing agents.

\section{References}

[1] Stoop, J.M.H., Williamson, J.D. and Pharr, M. (1996) Manitol Metabolism in Plants: A Method for Coping with Stress. Trends in Plant Science, 1, 139-144. http://dx.doi.org/10.1016/S1360-1385(96)80048-3

[2] Negm, F.B. and Loeschier, W.H. (1981) Characterization and Partial Purification of Aldose-6-Phosphate Reductase (Alditol-6-Phosphate:NADP 1-Oxidoreductase) from Apple Leaves. Plant Physiology, 67, 139-142.

http://dx.doi.org/10.1104/pp.67.1.139 
[3] Noiraud, N., Maurousset, L. and Lemoine, R. (2001) Transport of Polyols in Higher Plants. Plant Physiology Biochemistry, 39, 717-728. http://dx.doi.org/10.1016/S0981-9428(01)01292-X

[4] Belitz, H.D., Grosch, W. and Schieberle, P. (2009) Fruits and Fruit Products. Food Chemistry, 34, 807-861.

[5] Ball, G.F.M. (1990) The Application of HPLC to the Determination of Low Molecular Weight Sugars and Polyhydric Alcohols in Foods: A Review. Food Chemistry, 35, 117-152. http://dx.doi.org/10.1016/0308-8146(90)90026-Z

[6] Miyagi, M., Yokoyama, H. and Hibi, T. (2007) Sugar Microanalysis by HPLC with Benzoylation: Improvement via Introduction of a C-8 Cartridge and a High Efficiency ODS Column. Journal of Chromatography B, 854, 286-290. http://dx.doi.org/10.1016/j.jchromb.2007.04.044

[7] Oehlke, J., Brudel, M. and Blasig, I.E. (1994) Benzylation of Sugars, Polyols and Amino Acids in Biological Fluids for High-Performance Liquid Chromatographic Analysis. Journal Chromatography B: Biomedical Science Applied, 655, 105. http://dx.doi.org/10.1016/0378-4347(94)00067-0

[8] Ribeiro, F.A.L., Ferreira, M.M.C., Morano, S.C., Da Silva, L.R. and Schneider, R.P. (2008) Validation Spreadsheet: A New Tool for Estimating the Analytical Figures of Merit for the Validation of Univariate Methods. Quimica Nova, 31, 164-171. http://dx.doi.org/10.1590/S0100-40422008000100029

[9] Meyer, V.R. (1996) Theoretical Principles. In: Practical High-Performance Liquid Chromatography, John Wiley \& Sons, Hoboken, 17-45.

[10] International Conference on Harmonisation (ICH) (1995) Guidance for Industry Q2A: Text on Validation of Analytical Procedures.

[11] International Conference on Harmonisation (ICH) (1996) Guidance for Industry Q2B: Text on Validation of Analytical Procedures.

[12] Danzer, K. and Currie, L.A. (1998) Guidelines for Calibration in Analytical Chemistry. Pure and Applied Chemistry, 70, 993.

[13] Podder, S., Choudhury, J. and Roy, S. (2007) Secondary Benzylation with Benzyl Alcohols Catalyzed by a HighValent Heterobimetallic Ir-Sn Complex. Journal of Organic Chemistry, 72, 3129-3132. http://dx.doi.org/10.1021/jo0625094

[14] Muir, J.G., Rose, R.Y., Rosella, O., Liels, K., Barrett, J.S., Shepherd, S.J. and Gibson, P.R. (2009) Measurement of Short-Chain Carbohydrates in Common Australian Vegetables and Fruits by High-Performance Liquid Chromatography (HPLC). Journal Agricultural and Food Chemistry, 57, 554-565. http://dx.doi.org/10.1021/jf802700e

[15] Oura, Y., Yamada, K., Shiratake, K. and Yamaki, S. (2000) Purification and Characterization of a NAD ${ }^{+}$-Dependent Sorbitol Dehydrogenase from Japanese Pear Fruit. Phytochemistry, 54, 567-572. http://dx.doi.org/10.1016/S0031-9422(00)00158-8

[16] Wrolstad, R.E. and Shallenberger, R.S. (1981) Free Sugars and Sorbitol in Fruits a Complilation from the Literature. Journal of the Association of Official Analytical Chemists, 61, 91-103. 
Scientific Research Publishing (SCIRP) is one of the largest Open Access journal publishers. It is currently publishing more than 200 open access, online, peer-reviewed journals covering a wide range of academic disciplines. SCIRP serves the worldwide academic communities and contributes to the progress and application of science with its publication.

Other selected journals from SCIRP are listed as below. Submit your manuscript to us via either submit@scirp.org or Online Submission Portal.
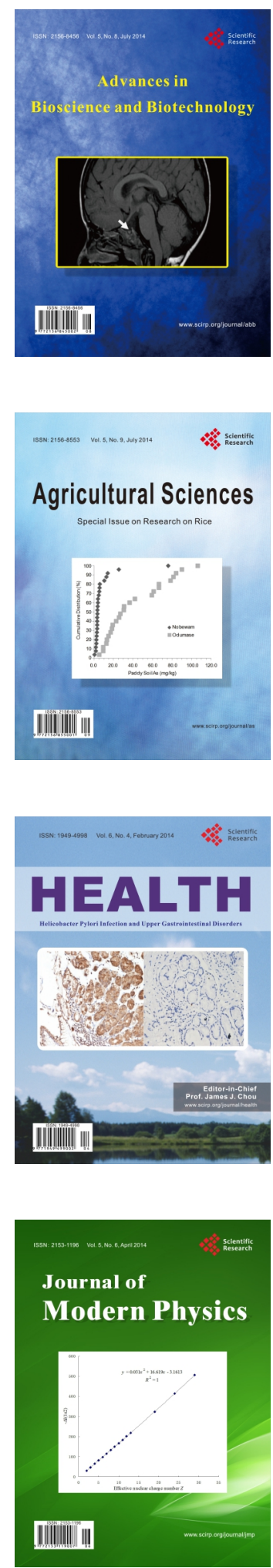
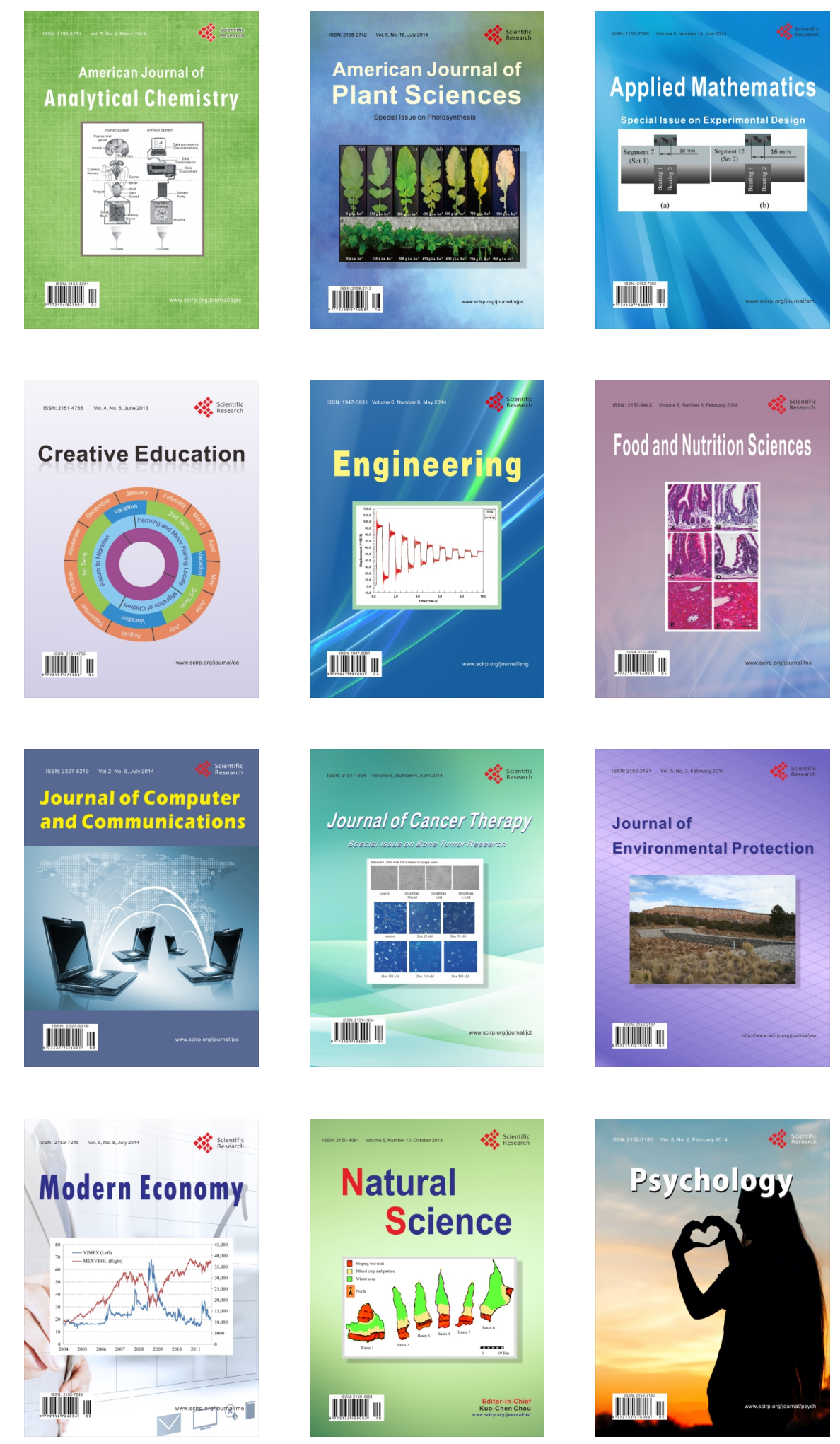